\title{
Gastroprotective Effect of Serjania erecta Radlk (Sapindaceae): Involvement of Sensory Neurons, Endogenous Nonprotein Sulfhydryls, and Nitric Oxide
}

\author{
Ana Paula Corrêa Castelo Branco Nappi Arruda, Roberta Gomes Coelho, ${ }^{2}$ Neli Kika Honda, \\ Catharine Ferrazoli, ${ }^{1}$ Arnildo Pott, ${ }^{3}$ and Clélia Akiko Hiruma-Lima ${ }^{1}$ \\ ${ }^{1}$ Physiology Department, Biosciences Institute, São Paulo State University-UNESP, Botucatu, São Paulo; and ${ }^{2}$ Chemistry \\ and ${ }^{3}$ Biology Departments, Federal University of Mato Grosso do Sul, Campo Grande, Mato Grosso do Sul, Brazil
}

\begin{abstract}
The present study reveals the pharmacological action of Serjania erecta Radlk. (Family Sapindaceae), an important medicinal plant species used in the Brazilian Pantanal against gastric pain. The methanolic (Me) and chloroformic (Se) extracts obtained from leaves of $S$. erecta were challenged by a very strong necrotizing agent in rodents, absolute ethanol. Se was also confronted with a nitric oxide synthase inhibitor $\left(N^{\mathrm{G}}\right.$-nitro-L-arginine methyl ester), a capsaicin cation channel transient receptor potential vanilloid type 1 antagonist (ruthenium red), or a sulfhydryl-blocker ( $N$-ethylmaleimide) to evaluate the participation of these cytoprotective factors in gastroprotection. In an in vivo experimental model, Me and Se presented several degrees of gastroprotective action without signs of acute toxicity. The best gastroprotective effect was restricted to all doses of Se. The mechanisms involving the gastroprotective action of Se are related to an augmented defense mechanism of the gastrointestinal mucosa consisting of sensory neurons, nitric oxide, and sulfhydryl groups that prevent and attenuate the ulcer process. The presence of polyisoprenoids in the Se explains the potent gastroprotective action of this medicinal species. Effective gastroprotective action and the absence of acute toxicity indicate this species may be a promising herbal drug against gastric disease.
\end{abstract}

KEY WORDS: • endogenous sulfhydryls $\bullet$ gastroprotective action $\bullet$ nitric oxide $\bullet$ Sapindaceae $\bullet$ sensory neurons $\bullet$ Serjania erecta

\section{INTRODUCTION}

$\mathbf{T}$ HE GASTRIC MUCOSA maintains structural integrity and function despite continuous exposure to noxious factors. The mucosal integrity is maintained by defense mechanisms, which include pre-epithelial factors, an epithelial "barrier," continuous cell renewal accomplished by proliferation of progenitor cells, continuous blood flow through mucosal microvessels, an endothelial "barrier," sensory innervations, and generation of prostaglandins and nitric oxide. ${ }^{1}$ Pharmacological therapy against gastric ulcer has been developed by compounds that fortify the gastric mucosa barrier and prevent mucosal damage from noxious factors. Serjania erecta Radlk. is a medicinal plant popularly known in Brazil as "retrato de teiú" or "cipó-cinco-folhas." Fruits of this genus are comestible, ${ }^{2}$ and their seed oils have an unusual distribution of fatty acid with high predominance of eicosanoid acid. ${ }^{3}$ This species is also widely used in folk medicine in tea form against inflammation, stomach ache, ulcerative diseases, and hypertension. ${ }^{4}$ Qualitative

Manuscript received 22 October 2008. Revision accepted 14 April 2009

Address correspondence to: Clélia Akiko Hiruma-Lima, Departamento de Fisiologia, Instituto de Biociências, São Paulo State University/Botucatu, Rubião Junior $s /{ }^{\circ} n, c p$ 510, CEP 18618-000, Botucatu, SP, Brazil,E-mail: hiruma@ibb.unesp.br phytochemical analysis of the hydroalcoholic extract obtained from stem and leaves of $S$. erecta showed the presence of saponins, flavonoids, triterpenoids, steroids, tannins, and catechins. ${ }^{5}$ Pharmacological evaluation of S. erecta showed topical anti-inflammatory activity in mice. ${ }^{5}$ The aim of the present study is to evaluate the gastroprotective action of two preparations of crude extracts from S. erecta leaves.

\section{MATERIALS AND METHODS}

\section{Animals}

All experiments were performed on male or female Swiss mice (weighing 25-35 g) or male Wistar rats (weighing 200-250 g) obtained from the Animal House of São Paulo State University, Botucatu, SP, Brazil. The São Paulo State University Institutional Animal Care and Use Committee approved all of the protocols used.

\section{Vegetal material and preparation of extracts}

Leaves of plants were collected in February 2006 in Cáceres, MS, Brazil and identified by Dr. Arnildo Pott and Vali Pott from EMBRAPA (Corumbá, MS, Brazil). Voucher specimens have been deposited under number HMS 8355 at 
the herbarium of EMBRAPA in Mato Grosso do Sul, Brazil. The dried leaves of $S$. erecta $(2 \mathrm{~kg})$ were separated, powdered through an electric grinder, and sieved through number 100 mesh. This material was then extracted exhaustively at room temperature with chloroform $(4 \mathrm{~L})$ or followed by methanol (4 L) (three times for 48 hours each). Solvents were completely evaporated at $35^{\circ} \mathrm{C}$ under reduced pressure to afford the chloroformic extract (Se) $(111.0 \mathrm{~g})$ and the methanolic extract (Me) (155.6 g).

\section{Gastric ulcer induced by different agents}

Rats were pretreated with vehicle (saline), positive control (carbenoxolone, $100 \mathrm{mg} / \mathrm{kg}$ ), Me, or Se from $S$. erecta leaves $(125,250$, or $500 \mathrm{mg} / \mathrm{kg})$. Then they were treated with absolute ethanol according to the method described by Morimoto et al. ${ }^{6}$ Finally, animals were sacrificed, and the stomachs were removed, opened along the greater curvature, and fixed between two glass plates. Each stomach was scanned in an HP scanner (Hewlett Packard, Palo Alto, CA, USA), and the images were stored for measurement of lesion areas with Avsoft ${ }^{\circledR}$ Bioview (Brazil) version 4.02 (image analysis software) to determine the gastric ulcerative area.

\section{Shay ulcer}

Mice were randomly divided into three groups treated orally or intraduodenally with $\mathrm{Se}(250 \mathrm{mg} / \mathrm{kg}$ [the dose that produces significant results in the acute experiment]), cimetidine $(100 \mathrm{mg} / \mathrm{kg})$, or vehicle (saline). Then pylorus ligature was performed as described by Shay ${ }^{7}$ followed by determination of the parameters for gastric juice volume, $\mathrm{pH}$, and total acid content of gastric secretion.

\section{Evaluation of participation of nitric oxide and sulfhydryl groups and/or sensory neurons}

Rats were divided into groups that had been treated previously with $\mathrm{N}$-ethylmaleimide (NEM) (Sigma Chemical Co., St. Louis, MO, USA) at the dose of $10 \mathrm{mg} / \mathrm{kg}, N^{\mathrm{G}}$ nitro-L-arginine methyl ester (L-NAME) (Sigma) at $70 \mathrm{mg} / \mathrm{kg}$, a transient receptor potential vanilloid (TRPV) antagonist (ruthenium red) (Sigma) at $6 \mathrm{mg} / \mathrm{kg}$, or saline. ${ }^{8}$ Thirty minutes later, the different groups received an oral dose of the vehicle, carbenoxolone $(100 \mathrm{mg} / \mathrm{kg})$, capsaicin $(4 \mathrm{mg} / \mathrm{kg})$, or Se $(250 \mathrm{mg} / \mathrm{kg})$. After 60 minutes, all groups were treated with $1 \mathrm{~mL}$ of absolute ethanol to induce gastric ulcer.

\section{Antioxidant activity}

The free radical scavenging assay evaluated Se at 40,80 , 160,320 , and $640 \mu \mathrm{g} / \mathrm{mL}$ to determine the ability of each dose to react with the stable 2,2-diphenyl-1-picrylhydrazyl (DPPH) free radical. ${ }^{9}$ The scavenging effect of the radical of each sample was calculated and compared with quercetin (Sigma) $(2.5,5,10,20$, and $40 \mu \mathrm{g} / \mathrm{mL})$. All the tests were conducted in triplicate. The antioxidant capacities were determined by the $\beta$-carotene/linoleic acid.

\section{Acute toxicity study}

This study was performed as described by Loomis and Hayes. ${ }^{10}$ The male and female mice $(n=10)$ received Se at a single dose of $5,000 \mathrm{mg} / \mathrm{kg}$, and the control group received saline $(10 \mathrm{~mL} / \mathrm{kg})$ by gavage. The mortality, measured body weight, and behavioral screening were recorded daily for 14 days after the oral treatment. The macroscopic analyses and weight of vital organs (liver, kidney, heart, lung, and spleen) were compared between animals treated with Se and those receiving the vehicle.

\section{Statistical analysis}

The results are presented as mean \pm SE values. Student's $t$ test was used to compare the two groups (acute toxicity), whereas three or more groups were compared by one-way analysis of variance followed by Dunnett's or Fisher's test with $P<.05$ considered significant.

\section{RESULTS AND DISCUSSION}

Alcohol is an etiological factor closely related to gastric mucosal damage. Intragastric absolute alcohol administration to rats that were fasted for 24 hours produced linear hemorrhagic lesions, extensive submucosal edema, mucosal friability, inflammatory cells, and epithelial cell loss in the stomach, which are typical characteristics of alcohol injury. ${ }^{11}$ The pathogenesis of ethanol-induced gastric mucosal damage occurs directly and indirectly through various mediators such as cyclooxygenase, lipoxygenase, cytokines, and oxygen-derived free radicals. ${ }^{12}$ Ethanol-induced gastric lesions also cause impairment of gastric defensive factors such as mucus and mucosa circulation. When compared to the control value, $S$. erecta Me significantly inhibited ulcerative lesions only at the highest dose $(500 \mathrm{mg} / \mathrm{kg})$. The best result was obtained after pretreatment with $S$. erecta $\mathrm{Se}$, which significantly inhibited ulcerative lesions at all doses tested (Table 1). Gomig et al. ${ }^{5}$ also observed that nonpolar

Table 1. EfFects of Me or Se from $S$. ERECTA on Gastric Lesions InduCED by ETHANOL In Rats

\begin{tabular}{lcc}
\hline $\begin{array}{l}\text { Treatment (p.o.), } \\
\text { dose }(\mathrm{mg} / \mathrm{kg})\end{array}$ & Area & Inhibition (\%) \\
\hline Vehicle (-) & $103.08 \pm 16.07$ & - \\
Carbenoxolone (100) & $34.08 \pm 5.50^{* *}$ & 67 \\
Me & & \\
$\quad 500$ & $44.20 \pm 8.01^{*}$ & 57 \\
250 & $58.57 \pm 11.32$ & - \\
$\quad 125$ & $108.71 \pm 16.69$ & - \\
Vehicle (-) & $312.16 \pm 56.85$ & - \\
Carbenoxolone (100) & $55.68 \pm 13.20^{* *}$ & 82 \\
Se & & \\
$\quad 500$ & $1.42 \pm 0.26^{* *}$ & 99 \\
250 & $36.89 \pm 13.68^{* *}$ & 88 \\
125 & $106.40 \pm 29.51^{*}$ & 65 \\
\hline
\end{tabular}

Data are presented as mean \pm SE values. Percentage of inhibition was in relation to the respective control group treated with their vehicle group.

By analysis of variance followed by Dunnett's test: ${ }^{P} P<.05, * * P<.01$. 
Table 2. Effects of Se from $S$. erecta on Gastric Lesions Induced by Ethanol in Rats Pretreated With NEM (a Sulfhydryl Blocker), Ruthenium Red (a Vanilloid RECEPTOR ANTAGONIST), OR L-NAME (AN INHIBITOR of Nitric Oxide Synthase)

\begin{tabular}{|c|c|c|}
\hline $\begin{array}{l}\text { Pretreatment (i.p.), } \\
\text { treatment (p.o.), } \\
\text { (dose }[\mathrm{mg} / \mathrm{kg}])\end{array}$ & Area & Inhibition (\%) \\
\hline $\begin{array}{l}\text { Saline }+ \\
\quad \text { Vehicle }(-)\end{array}$ & $75.54 \pm 16.52$ & - \\
\hline Carbenoxolone (100) & $5.77 \pm 4.20 * *$ & 92 \\
\hline Se $(250)$ & $18.75 \pm 8.63 * *$ & $75^{\mathrm{ab}}$ \\
\hline \multicolumn{3}{|l|}{$\mathrm{NEM}+$} \\
\hline Vehicle $(-)$ & $540.02 \pm 70.58$ & - \\
\hline Carbenoxolone (100) & $320.03 \pm 98.30 *$ & 40 \\
\hline Se $(250)$ & $485.25 \pm 109.26$ & $-^{\mathrm{a}}$ \\
\hline \multicolumn{3}{|l|}{ L-NAME + } \\
\hline Vehicle $(-)$ & $480.25 \pm 122.73$ & - \\
\hline Carbenoxolone (100) & $198.94 \pm 39.42 *$ & 58 \\
\hline Se $(250)$ & $427.21 \pm 45.46$ & $-\mathrm{b}$ \\
\hline \multicolumn{3}{|l|}{ Saline +} \\
\hline Vehicle $(-)$ & $272.64 \pm 60.25$ & - \\
\hline Capsaicin (4) & $3.87 \pm 1.27 * * *$ & 98 \\
\hline $\mathrm{Se}(250)$ & $91.41 \pm 22.16^{* *}$ & $66^{\mathrm{c}}$ \\
\hline \multicolumn{3}{|l|}{ Ruthenium red +} \\
\hline Vehicle $(-)$ & $515.85 \pm 56.70$ & - \\
\hline Capsaicin (4) & $114.45 \pm 25.65^{* * *}$ & 77 \\
\hline $\mathrm{Se}(250)$ & $314.41 \pm 102.72$ & $-^{\mathrm{c}}$ \\
\hline
\end{tabular}

NEM was used at $10 \mathrm{mg} / \mathrm{kg}$, ruthenium red was used at $70 \mathrm{mg} / \mathrm{kg}$, and L-NAME was used at $6 \mathrm{mg} / \mathrm{kg}$. Data are mean \pm SE values. Percentage of inhibition was in relation to the respective control group treated with vehicle. By analysis of variance followed by Dunnett's test: $* P<.05$, $* * P<.01$, $* * * P<.0001$.

${ }^{\text {a }}$ Saline + Se versus NEM + Se, significantly different by Fisher's test $(P<.05)$.

${ }^{\mathrm{b}}$ Saline + Se versus L-NAME + Se, significantly different by Fisher's test $(P<.05)$.

${ }^{\mathrm{c}}$ Saline + Se versus ruthenium red $+\mathrm{Se}$, significantly different by Fisher's test $(P<.05)$.

fraction from $S$. erecta acts against inflammation by inhibiting edema formation and leukocyte migration, whereas the polar fraction was ineffective as an anti-inflammatory. Because the most promising results were obtained using Se, we continued our studies in the subsequent assays with the purpose of investigating the probable anti-ulcerogenic mechanism involved in the action promoted by this extract.

It is well known that pylorus ligature causes gastric hypersecretion but that free radicals also are involved in the pathogenesis caused in this experimental model. Migration of neutrophils into the mucosa following pyloric ligation suggests that these cells may be involved in gastric mucosal injury, possibly by releasing free radicals that cause lipid peroxidation and damage to the cell membrane. ${ }^{13}$ Animals pretreated with Se (data not shown) did not present altered gastric juice parameters, a result that corroborates the absence of antisecretory activity of Se.

The synthesis of mucus that strengthens the mucosal barrier against harmful agents also serves as an important function in gastric protection. Accordingly, the literature reports that endogenous nonprotein sulfhydryl compounds are key agents in mucosal protection against ethanolinduced gastric injury. ${ }^{14}$ Usually, the growth in damage is accompanied by a decrease in the concentration of mucosal nonprotein sulfhydryl compounds because the sulfhydryl groups bind to the free radicals formed because of the action of noxious agents. Pretreatment of animals with a sulfhydrylblocker (NEM) markedly increased gastric lesions of Setreated animals (Table 2). These results indicated a strong involvement of endogenous nonprotein sulfhydryl in the gastroprotective effect of this extract. Nonprotein sulfhydryl compounds may be involved in scavenging oxygen-derived free radicals and controlling the production and nature of mucus. ${ }^{15}$

It is well known that nitric oxide is involved in the modulation of gastric mucosal integrity and is important in the regulation of acid and alkaline secretion, mucus secretion, and gastric mucosal blood flow. ${ }^{16}$ In the present study two complementary test systems-DPPH free radical scavenging and $\beta$-carotene/linoleic acid systems-were utilized. DPPH radical has been reported as a stable free radical to determine antioxidant activity of natural compounds. ${ }^{9}$ The method is based on the reduction of alcoholic DPPH solution in the presence of a hydrogen-donating antioxidant due to the formation of nonradical DPPH-H. ${ }^{17}$ In the $\beta$-carotene/linoleic acid assay the antioxidant capacity is determined by measuring the inhibition of the organic compounds and the conjugated diene hydroperoxides

Table 3. Evaluation of the Acute Toxicity of the Se from $S$. erecta in Male and Female Mice

\begin{tabular}{|c|c|c|c|c|c|c|}
\hline \multirow[b]{2}{*}{ Sex, treatment (dose) } & \multicolumn{6}{|c|}{ Organ weight/body weight ratio } \\
\hline & Liver & Lungs & Heart & Spleen & Kidney & Mortality \\
\hline \multicolumn{7}{|l|}{ Male } \\
\hline Vehicle (一) & $14.88 \pm 0.44$ & $5.35 \pm 0.34$ & $3.75 \pm 0.10$ & $4.22 \pm 0.17$ & $4.13 \pm 0.14$ & $0 / 10$ \\
\hline $\mathrm{Se}(5 \mathrm{~g} / \mathrm{kg})$ & $14.84 \pm 0.23$ & $5.11 \pm 0.14$ & $3.95 \pm 0.05$ & $4.37 \pm 0.14$ & $4.37 \pm 0.14$ & $0 / 10$ \\
\hline \multicolumn{7}{|l|}{ Female } \\
\hline Vehicle $(-)$ & $13.11 \pm 0.14$ & $4.17 \pm 0.07$ & $3.98 \pm 0.10$ & $4.02 \pm 0.17$ & $4.02 \pm 0.17$ & $0 / 10$ \\
\hline $\mathrm{Se}(5 \mathrm{~g} / \mathrm{kg})$ & $14.27 \pm 0.75$ & $4.81 \pm 0.17$ & $4.07 \pm 0.06$ & $4.19 \pm 0.24$ & $4.19 \pm 0.24$ & $0 / 10$ \\
\hline
\end{tabular}

Data are mean \pm SE values.

By analysis of variance followed by Dunnett's test: $P>.05$. 
arising from linoleic acid oxidation. ${ }^{9}$ The Se exhibited appreciable scavenging activity ranging from $4.77 \%$ to $66.25 \%$ in comparison to quercetin standard $(40 \mu \mathrm{g} / \mathrm{mL})$ $(94.32 \%)$. The peroxidation inhibition values ranged from $12.65 \%$ to $86.33 \%$, whereas the butylated hydroxytoluene standard $(40 \mu \mathrm{g} / \mathrm{mL})$ was $90.65 \%$. The results showed that the antioxidant activity measured by the $\beta$-carotene/linoleic acid assay at the same concentrations was higher than that of DPPH scavenging. This may be attributed to substances present in this extract such as polyisoprenoids that we observed for the first time in this extract. These polyisoprenoids exhibit antioxidant activity not only by donating hydrogen but also by scavenging oxygen.

The antioxidant activity of Se was also confirmed by another assay in which we observed that pretreatment with L-NAME (a nitric oxide synthase inhibitor) alters the cytoprotection of the gastric mucosa (Table 2). The gastroprotective effect produced by Se was significantly reduced by pretreatment with L-NAME. All these results taken together indicate a significant antioxidant property of Se and suggest an involvement of this extract in the protective effect against absolute ethanol-induced oxidative stress in the stomach. Our phytochemical analyses determined that Se presents mainly polyisoprenoids in its composition, and Murakami et al. ${ }^{18}$ reported that polyisoprenoids, such as geranylgeranylacetone, may be used to treat peptic ulcers because of their ability of increasing the defense mechanisms of the gastric mucosa.

Recent studies have shown that, in the stomach, sensory nerves influence the formation of gastric ulcer in a defensive manner. ${ }^{19}$ Capsaicin is widely used as a tool to affect capsaicin-sensitive afferent nerves. Capsaicin specifically targets the afferent sensory nerves via TRPV type 1 (TRPV1). Capsaicin in low concentration protects against gastric injuries induced by ethanol. This effect is attributed to stimulation of the sensory nerve endings. As expected, rats pretreated with ruthenium red (a capsaicin cation channel TRPV-1 antagonist) removed all cytoprotection from gastric mucosa. Treatment with capsaicin (positive control) plus ruthenium red was effective in protecting gastric mucosa against the injurious agent ruthenium red (77\%). But, rats pretreated with ruthenium red and Se showed increased levels of gastric lesion (Table 2). From these findings we conclude that Se also induced gastroprotection by enhancing the recovery of gastric mucosa by stimulating sensitive afferent nerves.

A single oral administration of $\mathrm{Se}$ at the dose of $5,000 \mathrm{mg} / \mathrm{kg}$ produced neither signs nor symptoms of acute toxicity in treated animals. During the 14 days following Se administration, no animal died, and no significant changes in daily body or organ weights were observed until the end of this period (Table 3). At autopsy, no significant changes or lesions were macroscopically observed in the internal organs of any animal. Loomis and Hayes ${ }^{10}$ described the classification of some chemical agents into toxicity categories in which the dose of $5 \mathrm{~g} / \mathrm{kg}$ was defined as practically nontoxic. Accordingly, this result indicates that $S$. erecta presents no acute toxicological effect when administered orally in male and female mice.

In conclusion, the data obtained demonstrated the gastroprotective activity of the Se from $S$. erecta leaves. This effect involves an augmented defense mechanism of the gastric mucosa, evidenced by the strong participation of nitric oxide and sulfhydryl groups, and by stimulating sensitive afferent nerves that prevent and attenuate the ulcer process.

\section{AUTHOR DISCLOSURE STATEMENT}

No competing financial interests exist.

\section{REFERENCES}

1. Laine L, Takeuchi K, Tarnawski A: Gastric mucosal defense and cytoprotection: bench to bedside. Gastroenterology 2008;135: 41-60.

2. Pott A, Pott VJ, Sobrinho AB: Plantas úteis à Sobrevivência no Pantanal. EMBRAPA, Corumbá, Brazil, 2004, p. 5.

3. Mayworm MA, Salatino A: Fatty acid composition of 'Cerrado' seed oils. J Sci Food Agric 1996;72:226-230.

4. Pott A, Pott VJ: Plantas do Pantanal. EMBRAPA, Planaltina, Brazil, 1994, p. 263.

5. Gomig F, Pietrovski EF, Guedes A, Dalmarco EM, Calderari MT, Guimarães CL, Pinheiro RM, Cabrini DA, Otuki MF: Topical anti-inflammatory activity of Serjania erecta Radlk (Sapindaceae) extracts. J Ethnopharmacol 2008;118:220-224.

6. Morimoto Y, Shimohara K, Oshima S, Sukamoto T: Effects of the new anti-ulcer agent KB-5492 on experimental gastric mucosal lesions and gastric mucosal defensive factors, the compared to those of terprenone and cimetidine. Jpn J Pharmacol 1991; 57:495-505.

7. Shay H: The simple goes the uniform production of gastric ulceration in rat. Gastroenterology 1945;5:43-61.

8. Matsuda H, Pongpiriyadacha Y, Morikawa T, Kashima Y, Nakano K, Yoshikawa M: Protective effects of polygodial and related compounds on ethanol-induced gastric mucosal lesions in rats: structural requirements and mode of action. Bioorg Med Chem Lett 2002;12:477-482.

9. Tepe K, Daferera D, Sokmen A, Sokmen M, Polissiou M: Antimicrobial and antioxidant activities of the essential oil and various extracts of Salvia tomentosa Miller (Lamiaceae). Food Chem 2005;90:333-340.

10. Loomis TA, Hayes AW: Essentials of Toxicology, $4^{\text {th }}$ ed. Academic Press, London, 1996, pp. 33-46.

11. Franke A, Teyssen S, Singer MV: Alcohol-related diseases of the esophagus and stomach. Digest Dis Sci 2005;23:204-213.

12. Abdel-Salam OM, Czimmer J, Debreceni A, Szolcsanyi J, Mozsik G: Gastric mucosal integrity: gastric mucosal blood flow and microcirculation. An overview. J Physiol Paris 2001;95: $105-127$.

13. Rastogi L, Patnaik GK, Dikshit M: Free radicals and antioxidant status following pylorus ligation induced gastric mucosal injury in rats. Pharmacol Res 1998;38:125-132.

14. Szabo S, Vattay P: Experimental gastric and duodenal ulcers. Advances in pathogenesis. Gastroenterol Clin North Am 1990;19:67-85. 
15. Salim AS: Sulfhydryl-containg agents: new approach to the problem of refractory peptic ulceration. Pharmacology 1993;46:281-288.

16. Chandranath SI, Bastaki SM, Singh J: A comparative study on the activity of lansoprazole, omeprazole and PD-136450 on acidified ethanol- and indomethacin-induced gastric lesions in the rat. Clin Exp Pharmacol 2002;29:173-180.

17. Sultana B, Anwar F, Przybylski R: Antioxidant activity of phenolic components present in barks of Azadirachta indica, Ter- minalia arjuna, Acacia nilotica, and Eugenia jambolana Lam. trees. Food Chem 2007;104:1106-1114.

18. Murakami M, Oketani K, Fujisaki H, Wakabayashi T, Ohgo T: Antiulcer effect of geranylgeranylacetone, a new acyclic polyisoprenoid on experimentally induced gastric and duodenal ulcers in rats. Arzneimittelforschung 1981;31:799-804.

19. Evangelista S: Role of sensory neurons in restitution and healing of gastric ulcers. Curr Pharm Des 2006;12:2977-2984. 